\title{
The Major Issues of English Language Teaching in Rural Areas in India
}

\author{
A.G. Vadivelan, P. Pandia Rajammal
}

\begin{abstract}
Language is one of the streams of communicating our thoughts, sentiments and feelings. Also, on the off chance that we consider language in display world then English is a standout amongst the most utilized dialects on the planet and English is utilized as a second dialect in India. Essential level English educational programs execution is fundamental in India to accomplish the set English language competency in the provincial regions. This paper explores to acquire the issues identified with the Problems of showing English in the rural school of India and also is attempting to provide some corrective measures for the enrichment of students belong to the rustic territories of India.
\end{abstract}

Keywords: English Language, Skill Development, Communication, Language Training, Rural Students

\section{INTRODUCTION}

English Language Teaching in provincial regions is a quite demanding undertaking, numerous mental, semantic, institutional and different components meet to extract the language of English teaching in country territories a virtual Gordian bunch, and learning of English in a disheartening knowledge (Guilherme, 2007; Kayman, 2004; Nunan, 2003). The Historical and the economic factors muddle the solemn section (Foley, 2007). The inaccessibility of the geological area from colossal focuses of learning such as in municipal urban areas and urban slumps deny the rustic regions of a few formative and scholastic advantages (Davidson, 2007; Holland, 2002; Warschauer, 2000). The non-accessibility of illuminated and capable English educators in towns hoses the possibilities of successful curricular exchange to make taking in a charming and remunerating knowledge (Rogers, 1976), The non-work introduction of the subjects of arts prevents the understudies from being diligent to ace a perplexing dialect as English (Tardy, 2004), Pupils falter their opportunity in a languid way (Flowerdew, 2000), None of the instructive partners is impeccably sufficiently fit in provincial regions to enable students to ace the twisted idea of the English language with its bizarre idioms (Kassim and Ali, 2010), notorious spelling systems and queer pronunciation (in light of the fact that there is not really any balanced correspondence between the letters of the letters in order and their elocution) (Graham, 1987).

Revised Manuscript Received on December 29, 2019.

* Correspondence Author

Dr. A.G. Vadivelan., English department, Kalasalingam Academy of Research and Education, Krishnankoil, Tamil Nadu, India. vadivelanag@gmail.com

SecDr. P. Pandia Rajammal, English department, Kalasalingam Academy of Research and Education, Krishnankoil, Tamil Nadu, India. Pandiarajammal.p@klu.ac.in
It seems to very difficult to find anyone correspondingly at ease with the four skills in language such as listening, speaking, reading and writing - and having a laudable mastery of all these four (Lillis and Curry, 2006; Pakir, 1999; Peregoy and Boyle, 2000). Some compose well, yet need fluency in talking; some talk, yet need great elocution (Demie, 2013). The individuals who talk fluidly regularly end up being poor at composing (Demie and Strand, 2006). Great English educating ought to agreeably mix the dominance of these four skills (Gonzalez, 2000). In any case, it is by all accounts a removed outlook for the country competitors of English (Andrade, 2006). This research paper endeavours to obtain a closer book in the different types of issues which the provincial ELT situation is overwhelmed in, and recommends a couple of attainable answers for unravel it and turn it a vivifying power to cheer up the countryside learning set-up.

\section{SIGNIFICANT ISSUES}

The significant issues that harm ELT in country zones might be advantageously inspected under the accompanying heads.

\section{A. Defective Pedagogy}

The instructional method embraced in teaching English, alike in provincial and urban zones, shows genuine blemishes. Still now it has concentrated on the composed frame and ignored the verbal skill. Additionally the listening and the reading skills were likewise not legitimately and at the same time dealt with. Any learning of language ought to be communication oriented (in the underlying stages, in any event). The Skills of Listening, speaking, reading and writing that ought to be the regular order.

Obviously, language structure authority is a Must in composed English. Be that as it may, communicate in English need not be choked by an inflexible loyalty to it. Numerous circular and abbreviated articulations are allowed in the casual approach, also the various casual uses/slang. Linguistic amenities are disregarded in real discourse involvement. Be that as it may, these variables were.

As the National Knowledge Commission (2006) appropriately called attention to, "lack of contextualization of the pedagogy of English" was a central purpose behind the disappointment of students to gain legitimate authority of English. The language of Contextualized as in plays, stories, and so on, could be tested through our body language, single-word replies, or even through our mother-tongue. 
Satisfactory introduction to this contextualized dialect fortifies the students' mastery in English. The method using 'Chalk and talk' strategy of an authoritarian instructor or a teacher was a stifling background for students. In the event that the instructor is a magnificent conversationalist, this lecture-method can't be blamed, yet the circumstance is frequently extraordinary.

\section{B. Inept Teachers}

The teachers ought to be ideal of good language in their language skill. A significant number of the teachers talk in imposing language, in a broken way, bobbling for correct words and the correct articulations and frequently wavering. Some are so quick (in talking) to be effortlessly seen, yet others to ease back to energize any enthusiasm for the audience members. On the off chance that some influence a remote highlight, some others blunder on the opposite side by talking with net local quirks building English fewer comprehensible. After these insignificant instructive necessities for arrangement, a great number of instructors take into the grand field of educating, regularly in the wake of paying the administration gigantic aggregates as gifts. This can't in itself be held the prime reason for the decrease in gauges. What happens truth be told is the degeneration of the instructor into one that changes teaching into an ordinary activity without tasteful availability for the class and satisfactory related perusing. The moment he stops scrutinizing books and periodicals, his mental horizon begins to pull back and the empowering of data winds up freakish. Quality instructors read a great deal of books about what their abilities and keep alive their scholarly intrigue. The people who basically would like to educate as a sheltered business and grasp the rationale of life: 'eat, drink, and be cheerful', pulverize it irredeemably. In the occasion that educating is a profound established learning process, instructors need to search out learning. The main thing is the genuine idea of the educators and their vitality for better instructing. It is their insight and successful method of conveyance that really checks. Unimportant writing dependent educators can't prepare the understudies in aptitudes.

\section{Tilted educational program}

The instructive program all around don't offer the materials for the inside and out progress of the aptitudes, They are significant and uneven for the composed structure and pressed in wiped out picked showing materials, They request simply composed examination hence end up being the most noticeably terrible thing about understudies rather than a blessing. Inadequate preparing materials prescribed in the prospectus don't help the specialist of English. Training materials should be understudy cordial, correspondence centered and work arranged. These should be adequately clear and charming for understudies. Rustic understudies are oftentimes repelled by the very requesting and troubling nature of the by and by prescribed prospectuses followed in most Indian universities. In addition, it is writing loaded and drained of language experience.

\section{The Psychological imperatives}

A decent number of rustic understudies in schools are from the first generation. They do not have any scholastic and scholarly point of reference to draw motivation from. They are essentially befuddled and do not have any genuine scholarly inspiration to seek after more profound language studies and higher Intellectual interests. Their insensible guardians and kin don't outfit them - any Intellectual foundation and the fundamental goad. Consequently, they stay indifferent towards their examinations. English language learning is no charming an activity from their social perspective. They are an outsider to the ethos of the English language also. Again, many students are famished children of the poor farmers. They experience the ill effects of destitution and rationally from the feeling of inadequacy. The Indian understudies achieve schools with preferences against English as the language of their one-time oppressors, the British individuals. A couple of understudies dread English is an irksome tongue and outside their capacity to get it. Most understudies accomplish colleges with poor English learning and meager language experience hailing from unacceptable schools. All these antagonistically influence ELT in provincial territories and make it no not exactly a nightmarish encounter.

\section{E. Environmental settings}

Towns are overall arranged far from urban regions and towns. This remoteness is an excessive number of a hopeful instructor to settle in towns. Along these lines most quality educators are careful of serving in towns and hail to urban territories for solace and calling Prospects, This leaves the towns to be content with the unremarkable instructors who disregard to improve the English standard of rustic understudies. Once more, urban areas are honoured with a plentiful supply of a wide range of educating learning materials and current articles of showing gear, for example, the PCs, though the villages do not have all these, alongside the periodicals and even the English newspapers. Besides, the numerous job opportunities in cities goad students into learning and feel quite helpless economically to hunt for jobs in the cities. The odds of presentation to English in urban communities are in abundance whereas it is insufficient in provincial territories. All these militate against the chances of rural students gaining good English language mastery and stance as hindrances to English Language Teaching.

\section{SUGGESTIONS FOR IMPROVEMENTS}

- The focus ought to be given by the teachers on enriching the Skill Development and modification in favour of oral practices than written practice in the classroom

- While teaching the grammar, the necessity ought to be given to the useful aspects rather than the formal.

- Tutors must be updated in Phonetics and Communicative English; they should help students acquire an acceptable pronunciation and a fair degree of fluency. 
- Facilitate - Spoken English Course for the willing students.

- Make use of modern technology such as computers, OHP, LCD and establish language labs in rural areas.

- Assist the students to enrich a neutral accent, purging their English. Of M. T Interference (especially syllable-timed rhythm), and coach them to acquire the stress- timed rhythm peculiar to the English language.

- The teacher ought to speak English at a moderated pace uttering every word clearly. He should not be too fast, inaudible, incoherent or inarticulate. What he speaks should be very clear; his pronunciation should be exemplary and verbal mastery commendable.

- Audio/Visual can be used effectively to listen to news and other English programmes. Tape recorders are excellent for listening to Spoken English Cassettes of the $B B C / C I E F L$. This is quite practical in rural areas where the computers are not easily available. CD/DVDs can be effectively used wherever computers and CD/DVD players available. Frequent listening by students to such cassettes/CDs helps them to identify and acquire the correct English sounds.

- The association ought to be sufficiently sensible to choose the quality staff as opposed to influencing a prospering business to out of instructive foundations by taking enormous gifts from recently selected individuals from the staff who have neither inclination for showing nor the required quality. Just dedicated and qualified staff can enhance the standard of the students. There is no other panacea.

- Provide a lot of loud reading and silent reading training. Encourage library work and give assignments.

\section{CONCLUSION}

The dialect approach in school instruction developed as a social issue and individual issue. The nature of English language training in greater part of Indian schools displays an exceptionally shocking picture. Instructor's dialect capability, presentation of dialect and materials are significant worries for quality English language learning. Truly rural students' circumstance is extremely troublesome. They don't have open doors as city understudies had (i.e.) language learning lab, audio and video aids help and so forth. Most of the pupils in schooling consider English as a subject, not as a language. It is the primary snag of them. Lion's share of pupils studies English just for scoring marks in the examination. They are not known how to present ballads but rather they surely understood how to memory it. All things considered, rural students have a panic in English. Then again numerous educators don't have a long vision of pupils' life. They concentrate just on examination.

\section{REFERENCES}

1. Andrade MS (2006) International students in English-speaking universities: Adjustment factors. Journal of Research in International Education. DOI: 10.1177/1475240906065589.

2. Curry MJ and Lillis TM (2004) Multilingual scholars and the imperative to publish in English: Negotiating interests, demands, and rewards. TESOL Quarterly. DOI: 10.2307/3588284.

3. Davidson K (2007) The nature and significance of English as a global language. English Today. DOI: 10.1017/S0266078407001095

4. Demie F (2013) English as an additional language pupils: how long does it take to acquire English fluency? Language and Education. DOI: 10.1080/09500782.2012.682580.

5. Demie F and Strand S (2006) English language acquisition and educational attainment at the end of secondary school. Educational Studies. DOI: 10.1080/03055690600631119.

6. Flowerdew J (2000) Discourse Community, Legitimate Peripheral Participation, and the Nonnative-English-Speaking Scholar. TESOL Quarterly. DOI: 10.2307/3588099.

7. Foley JA (2007) English as a global language: My two satangs' worth. RELC Journal. DOI: 10.1177/0033688206076155.

8. Gonzalez A (2000) The acquisition and labor market value of four English skills: New evidence from NALS. Contemporary Economic Policy. DOI: 10.1111/j.1465- 7287.2000.tb00023.x.

9. Graham JG (1987) English Language Proficiency and the Prediction of Academic Success. Tesol Quarterly. DOI: 10.2307/3586500.

10. Guilherme M (2007) English as a Global Language and Education for Cosmopolitan Citizenship. Language and Intercultural Communication. DOI: 10.2167/laic184.0.

11. Holland R (2002) Globospeak? Questioning text on the role of english as a global language. Language and Intercultural Communication. DOI: $10.1080 / 14708470208668072$

12. Kassim H and Ali F (2010) English communicative events and skills needed at the workplace: Feedback from the industry. English for Specific Purposes. DOI:10.1016/j.esp.2009.10.002.

13. Kayman MA (2004) The state of English as a global language: Communicating culture. Textual Practice. DOI 10.1080/0950236032000140131.

14. Lillis T and Curry MJ (2006) Professional academic writing by multilingual scholars: Interactions with literacy brokers in the production of English-medium texts. Written Communication. DOI: $10.1177 / 0741088305283754$

15. Nunan D (2003) The Impact of English as a Global Language on Educational Policies and Practices in the Asia-Pacific Region. TESOL Quarterly. DOI: 10.2307/3588214.

16. Pakir A (1999) Connecting with English in the Context of Internationalization. Tesol Quarterly. DOI: 10.1002/mus.22013.

17. Peregoy SF and Boyle OF (2000) English Learners Reading English: What We Know, What We Need to Know. THEORY INTO PRACTICE. DOI: 10.1207/s15430421tip3904_7.

18. Rogers J (1976) English as an International Auxiliary Language. RELC Journal. DOI: 10.1177/003368827600700206.

19. Savas P (2012) Micro-teaching Videos in EFL Teacher Education Methodology Courses: Tools to Enhance English Proficiency and Teaching Skills Among Trainees. Procedia - Social and Behavioral Sciences. DOI: $10.1016 /$ j.sbspro.2012.09.558.

20. Tardy C (2004) The role of English in scientific communication: Lingua franca or Tyrannosaurus rex? In: Journal of English for Academic Purposes, 2004. DOI: 10.1016/j.jeap.2003.10.001.

21. Warschauer M (2000) The Changing Global Economy and the Future of English Teaching. TESOL Quarterly. DOI: 10.2307/3587741.

\section{AUTHORS PROFILE}

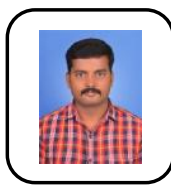

Dr. A.G. Vadivelan, PhD., graduated at Anna University, Tamil Nadu, India, presented and published papers at National and International Conference. Published papers at International Journals. Guided UG, PG Projects and MPhil Dissertation.

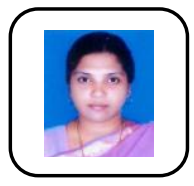

Dr. P. Pandia Rajammal, PhD., gruaduated at Madurai Kamaraj University, Tamil Nadu, India, presented papers at National and International Conference, published papers in Journal, Organied seminars and Guest Lectures, Guided PG projects and MPhil dissertations, working as an Assistant Professor at Kalasalingam Academy of Research and Education, Tamil Nadu, India. 